\title{
Granger Causal Relationship Between Bond Yield Changes and Equity Returns Through Wavelets Analysis: The Case of Turkey*
}

\author{
Remzi GÖK ${ }^{1}$ ㅇ, Erhan ÇANKAL ${ }^{2}$
}

\begin{abstract}
This paper re-examines the stock-bond relationship in Turkey by using weekly price observations of stock indices and interest rates over a sample period between 2005-04-01 and 2016-12-30. Considering heterogeneity investment periods, we employed both standard and wavelets methods to provide a deeper understanding. The findings suggest the presence of unit roots in our variables at the level and reveal evidence of the cointegration and a one-way causal relationship in the long-run. Given that the conventional time-domain tests document insignificant results, we employed causality tests on the decomposed series to unearth the true dynamics of causal linkages. Furthermore, the empirical results support the presence of bi-directional causality between the fluctuations in bond yields and equity returns, i.e. they are significant predictors of each other in the medium and long time horizons. The empirical results pertinent to asymmetric causality tests show a one-way causality from the negative shocks in stock prices to the positive shocks in interest rates. Specifically, the results of frequency causality test reveal that the predictive power of the financial index returns on the interest rate changes intensifies across frequencies.
\end{abstract}

Keywords: Wavelets, symmetric, asymmetric, and frequency causality

\section{Introduction}

Although it has been long debated, the stock-bond relationship is of great interest because bond yield is one of the major factors for asset valuations, particularly for stock and bond prices. The related literature has produced ambiguous and contradictory results regarding the cointegration and Granger causality of the stock-bond relationship due to the period and variables chosen and methodology employed by researchers. In other words, whether bond yields and equity prices move in the same or the reverse direction is hypothetically unclear since the current literature offers differing opinions on this association. This analysis has been a chief issue in economics and finance since it has significant practical implications for market agents for their asset allocation, risk management, and economy policy decisions. Therefore, our main objective is to study this relationship both at the aggregate and sectoral levels, including both financial and nonfinancial indices, since their valuations are also affected by interest rate movements even though interest rates have varying impacts and significance on their valuations.

In finance theory, many researchers have documented a significantly negative association between the bond yields (short- and long-term) and the equity prices, and it is widely explained by the dividend discount theory in Lynge and Zumwalt (1980), Campbell (1987) and Flannery and James (1984). Along with the correlation, the stock-bond relationship is also investigated in terms of cointegration and causality test using time- and frequency-domain tools. For examples, empirical studies that report causality from bond yields to equity prices are Rahman and Mustafa (1997), Erdem et al. (2005), Gan et al. (2006), Kasman et al. (2011), Jawaid and UI Haq (2012), Tiwari (2012), and Chia and Lim (2015). The papers that find causality from stock

*This research paper derived from the doctoral thesis titled "Wavelet analysis of stock returns and interest rate changes: evidence from Turkey" presented at the "ISEPA'18 II. Uluslararası Ekonomi, Siyaset ve Yönetim Sempozyumu" in Diyarbakır, Turkey.

${ }^{1}$ Arş. Gör. Dr., Dicle Üniversitesi IïBF, İşletme Bölümü, remzi.gok@dicle.edu.tr

${ }^{2}$ Dr. Öğr. Üyesi, Ankara YBU, İşletme Bölümü, ecankal@ybu.edu.tr, 
prices to interest rates are Wong et al. (2006), Acikalin et al. (2008), Mohanamani and Sivagnanasithi (2012), and Özer and Kamisli (2015). Furthermore, Wongbangpo and Sharma (2002), Çifter and Özün (2008), Jammazi et al., (2017), and Hui et al. (2017) reveal causality in both directions. However, Muradoglu et al. (2000), Bhattacharya and Mukherjee (2002), Türkyilmaz and Özata (2009), Forson and Janrattanagul (2014), Coşkun et al. (2016), and Alam and Rashid (2014) report no causality in neither direction. On the other hand, the studies that include cointegration results are Chan et al. (1997), Das (2005), and Humpe and Macmillan (2009). Chan et al. (1997) document insignificant cointegration results and assert that the tactical allocation strategy holds since the debt and capital markets do not move in tandem in the long-term.

This study stems from the necessity to offer a deeper understanding of the stock-bond relationship given that the current literature has produced ambiguous and contrasting results regarding the cointegration and causality of the two variables using only time-based methods. Specifically, we investigate whether or not a significant relationship exists over different time scales, and if so, measure the contribution of these time horizons to the overall causal interaction. The existence of the frequency-based relationship across different time horizons requires the need for active portfolio management and tactical asset allocation to minimize the portfolio's risk but maximize its return, and it is therefore of importance to implement both time and frequency domain analysis of the stock-bond linkages for their optimal portfolio decision. The findings reveal that our variables have a unit root with the conventional tests, whereas six out of them become stationary with the test of Lee and Strazicich (2003) at log-level. According to the Hatemi-J (2008) test, it is found that the null of a long-run relationship between the bond yields and equity indices cannot be rejected. Further, the findings of the VECM test provide significant unilateral short-run causality from the bond yields to BIST Holding and Investment, and one-way long-run causalities to BIST Financials, BIST Holding and Investment, BIST Textile Leather, BIST Tourism, and BIST Transportation indices. The results of the conventional causality approach demonstrate that the changes in bond yields are a reliable indicator of future growth in the stock indices in the time domain, but the wavelet-based findings reveal that the Granger causality goes in both directions in the higher scales, i.e., mid- long-term. Similarly, the findings of Breitung and Candelon (2006) method yields significant results that the changes in interest rates seem to appear Granger-causes both financial and nonfinancial stock index returns at significance level. Unsurprisingly, stock indices that have the most consistent significant power on the movement at different frequency intervals in interest rates are the financial indices. In addition, we find that the positive shocks from the interest rates Granger-cause the negative shocks in the financial indices and the negative shocks of twenty out of twenty-five index returns cause positive innovations in the bond yields. Overall, our empirical findings not only mostly consistent with the current theory and evidence on the equity-bond relationship but also provide a reliable time scale interpretation of the interaction, which is not achievable with standard analyzing tools.

This study proceeds as follows. In section 2, we give a brief literature overview of the equity-bond relationship. Section 3 introduces wavelets and unit root, cointegration, and causality tests, respectively. Section 4 presents the summary statistics for weekly variables from April 1, 2005, to December 30, 2016, and the empirical findings for Turkey. Lastly, section 5 offers concluding remarks for investors and policymakers and recommendations on future studies.

\section{Literature Review}

Çifter and Özün (2008) investigate the causal impacts of bond rate movements on equity prices using wavelets for Turkey. The sample period starts on January 2, 2003 and ends on February 22, 2006, of which sample size is 760 daily observations. The findings show that both variables in Turkey move in tandem in the long-run, and a one-way causal connection running from the equity prices to the bond rates over time exists. Applying causality tests to the decomposed series; however, they (2008) reveal that also a causal link from the bond rate changes to the share returns emerges. At shorter investment horizons corresponding to [1-8] days, the null hypothesis of no causation cannot be rejected; however, at medium and long scales, the changes in interest rates were found to lead the stock price movements beyond the third scale. Their empirical evidence, overall, showed that the bond rates had considerable long-term impacts on the equity prices, and market agents are recommended to follow the bond market volatilities for their investment and risk management decisions. In a different paper, Özün and Çifter (2006) assert a significant cointegration between the interest rates and stock index, XBANK, using 1145 daily observations for Turkey. The findings showed evidence of significant short- and long-term 
causality running from the interest rates to the banking index. By decomposing prices into different time scales, the null hypothesis of no short- and long-term causality strongly rejected at scales of $\mathrm{d} 1, \mathrm{~d} 2, \mathrm{~d} 3$, and $\mathrm{d} 6$.

In his paper, Tiwari (2012) analyzes the causal relationships between monthly equity prices and bond rates through the wavelet coherence approach in India over the sample period between 1990-M01 and 2009-M03. The results reveal that the interest rates have reciprocal causal relations with the Indian stock market, which intensifies over frequency and periods. Kumar and Puja (2012) report that the VECM results support the existence of unilateral long-run causality from the interest rate to the equity price over the sample period 1994M04-2011M06 in India. In a related paper, Andrieș et al. (2014) found significant connections among the monthly observations of stock prices, interest, and exchange rates (REER) in India through the wavelet coherence approach. The paper presents evidence of a significant relationship, i.e., both the bond and exchange rate fluctuations lead the equity price movements.

To study the dynamic equity-bond comovement, Jammazi et al. (2015) employ a time-varying DCC-GAR$\mathrm{CH}$ model. The data set includes 16 developed countries and covers the sample period between January 1993 and April 2013. The findings of this paper provide a time-dependant stock-bond comovement pattern for most countries, i.e., the association switches sign from positive (in the 1990s) to negative since early 2006 , implying a flight-to-quality fact. However, an affirmative bond-stock relationship is detected since late 2009 as a consequence of the debt crisis in Europe. Furthermore, they (2015) find out that the stock-bond comovement is the same both in the bearish and bullish markets, therefore, propose investors and portfolio managers to consider the time-varying character of the bond-equity relationship for their risk and portfolio management decisions.

By using monthly observations, Jawaid and UI Haq (2012) investigate the effects of the exchange and bond rates on the volatilities of the equity market over the sample period 2004:01 and 2010:12. They (2012) report evidence of significant cointegration and unidirectional causality between the short-term bond yields and the equity price in Pakistan. Investors are suggested to follow the fluctuations in the foreign exchange and the short-term bond rates before investment decisions on the banking industry since these two variables are influential factors in predicting future stock returns. The findings of the Barakat et al. (2015) paper, on the other hand, provide bidirectional causal relationships between the bond rates and equity prices in Tunisia and Egypt.

The objective of Amata et al. (2016) paper is to investigate the association between macroeconomic variables, investor herding behavior, and equity market volatility over the sample period 2001:01 and 2014:12, for a total of 167 monthly observations. They (2016) found significant support of the effect of the T-bill rate on the equity market volatility to be significantly positive. The finding of VECM presents evidence of short-term causality between the bond rates and the volatility in the NASI index at a 10\% significance level. They (2016) recommend a strict monetary policy and control of factors causing significant variations on the inflation rate and suggests a closely following the interest rate policy.

Coşkun et al. (2016) examine the macroeconomic variables-stock price relationship through impulse response function and causality test. The whole sample includes a total of 129 monthly observations of the interest rate, the exports, the imports, exchange rate, index of industrial production, gold price, and stock prices and covers the period 2005M01-2015M09. Evidence published in the paper purports unidirectional linear causalities running from XU100 to the industrial production, the exports, and imports, whereas a unique direction of causality running from the exchange rate to XU100 is indicated. There is no, however, a definitive pattern of interaction between XU100 and the interest rates. Furthermore, a one standard deviation shock to the interest rates (XU100) causes significant decreases in XU100 (the interest rates) for three periods.

Sensoy and Sobaci (2014) examined the dynamic relationship between the interest rates, exchange rates, and stock market in Turkey using daily observations data. The data covers the period from 2003-01-02 to 2013-09-05. The authors (2014) found out a significantly negative relationship between the stock market returns and the interest rate changes, supporting the theory of discounting dividends in stock price calculations. Besides, they (2014) revealed that its domestic problems did not cause the source of the upward volatility shifts observed in Turkey, indicating that the markets in Turkey were not immune to global political, economic, and financial conditions. Therefore, there was no need to take any reaction by the policymakers to prevent a long run contagion between the capital and money markets since the result with or without unexpected and severe interventions would be the same. The 
empirical results of Li et al. (2017) report a significantly negative relationship between stock prices and real interest rates in the long run in Malaysia. They (2017) identify a two-way short-run causal relationship between stock prices and real interest rates as well as portfolio investment flows and real interest rates, indicating that there exists a strong affiliation between the stabilities of the stock market and the interest rate.

The aim of Poyraz and Tepeli (2014) paper was to study the relationship between macroeconomic variables including inflation, money supply, gold prices, bond yields, and industrial production and stock prices over the period December 1995 to November 2011, for a total of $\mathrm{T}=192$ monthly observations for each variable. They (2014) provided evidence of bidirectional linear causalities between XU100 and interest rates at lags of 1 and 9 at the $10 \%$ significance level. Further, the paper found a unidirectional causal relationship running from the stock returns to the interest rate changes at 3, 6, and 12 monthly lags, i.e., share returns were found to exert significant lagged influences on the interest rates. Similar results are obtained by Aktaş and Akdağ (2013), who found strong evidence of the bidirectional causality between the deposit interest rate and the capacity utilization rate with stock market prices. Besides, the current value of inflation rate, exchange rates, and consumer confidence index was found to predict the future directions of the stock prices but not the other way around.

Özer and Kamisli (2015) investigated the causal relationship between the weekly data of macroeconomic factors and stock market index, XU030, over the sample period 2003-2015 using both the time and frequency-domain method for Turkey case. The empirical findings pertinent to the Breitung and Candelon (2006) frequency causality test show that there exists a unilateral causal relationship between medium and long-term. As dictated by the authors (2015), the reasons behind the no causality from interest rates to stock market are (i) phenomenal over-subscription of new issues, (ii) the booming stock market and (iii) controlling the interest rates, of which have significantly negative impacts on liquidity.

With the wavelet method, Moya-Martínez et al. (2015) studied the stock-bond market relationship at the industry level over the period 1993:01-2012:12 for Spain. The empirical findings reveal that the stock indices, particularly the regulated and highly indebted industries, are influenced significantly but negatively and at varying magnitudes from the movement interest rates. The results also report a scale-dependent causality between the share returns and the interest rate changes, i.e., the association is weak at shorter, but it becomes stronger and significant at the higher scales. Based on the Granger causality test, the movements in interest rates could be used to predict the stock returns of Technology and Telecom at scales of $d 1$ and d6; Industrials at scales of d5 and d6; Chemicals and Paper at scales of d4, d5, and d6; and Food and Beverages at scales of $d 3, d 4, d 5$, and $d 6$. The reverse causal relationship holds for Technology and Telecom at scales of $d 4$ and d6; Industrials at scales of $d 1$ and d6; Chemicals and Paper at scales of $\mathrm{d} 5$ and $\mathrm{d} 6$; and Food and Beverages at scales of d1, d2, d3, and d4. Similarly, the changes in interest rates Granger cause Banking and Financial Services at the lowest frequency (d6), whereas the causality runs in the reverse direction for Banking at scale $\mathrm{d} 4 \mathrm{and} \mathrm{d} 6$ and Financial Services at the highest scales. They (2015) suggest that their findings are, in overall, in line with their prior expectations and have substantial theoretical soundness, namely, longterm investors are more likely to follow macroeconomic fundamentals than short-term investors for their investment and risk management decisions, proving that interest rates are one of the key driving force of stock markets.

\section{Methodology and Data}

This section describes the methodological aspects of the paper, and it begins by presenting a brief review of the wavelets and goes on by a general discussion of the econometric approaches employed in the empirical analysis. To conserve space, however, we discuss only wavelets and the Breitung and Candelon (2006) frequency causality test.

\subsection{Wavelets}

One of the methodologies used for the paper is wavelets, which enable us to study the causal relationship of bond-stock markets for different time scales, i.e., in the short-, medium-, and long-run. Due to their versatility and convenience of being able to offer both time and frequency information of the underlying data or signal simultaneously, they have received tremendous attention from researchers in recent years. Wavelets, however, are introduced to overcome the limitations of Fourier analysis, of which does not require stationarity, an assumption not valid for most financial and macroeconomic variables, of data and local both in time and frequency through dilatations and translations, respectively. As the name advocates, wavelets are short 
or small waves, their admissible function integrates to zero, and grow and die out in the short-time because of having a finite length and oscillatory behavior (Soman et al., 2010).

Ramsey (2014) states that there are two basic wavelets: father $\phi(t)$ and mother $\psi(t)$ wavelet. The latter wavelet (known as the wavelet function) basically is squeezed (dilated) and shifted (translated) to capture the frequency and time information from the underlying time series, namely, it captures all deviations from the trend. This wavelet represents the detailed (high-frequency) parts and integrates to zero. Conversely, the former wavelet (known as the scaling function) integrates to one and reconstructs the smooth and trend (low-frequency) part of the data, namely, it extracts low-frequency components from the raw data. The approximating wavelet functions depending on normalization rules can be expressed as follows

$$
\psi_{j, k}(t)=2^{-\frac{j}{2}} \psi\left(\frac{t-2^{j} k}{2^{j}}\right) \quad \& \quad \phi_{J, k}(t)=2^{-\frac{J}{2}} \phi\left(\frac{t-2^{j} k}{2^{j}}\right)
$$

where $k$ and $j=1, \ldots, J$ index the translation and the scale, therefore, $2^{j} k=a$ and $2^{j}=b$ are defined as the translation parameters and the measure of the scale, respectively. It is known that the dilation factor $b$ controls the length of the window while $a$ is a measure of the location.

As stated by Gencay et al. (2002), one can disentangle the causal relation on a scale by scale basis which enables us to determine which time scales are contributing to the overall relation through the wavelet analysis in the context of multiresolution analysis (MRA) introduced by Mallat (1989). The MRA analysis gives a chance to obtain a scale-invariant interpretation of the underlying time series by shifting the window from low scales to high scales; therefore, it is possible to see the finest and coarsest details, in a manner of speaking, both the trees and the forest, respectively (Graps, 1995). Daubechies (1992) demonstrate that the transformation process of the MRA is performed through the pyramid (cascade) algorithm. The multiresolution approximation building up an underlying $X(t)$ variable from the coarsest scale downwards up to scale $J$ can be written by the following expression

$$
X(t)=S_{J}(\mathrm{t})+\sum_{j=1}^{J} D_{j}(\mathrm{t})=D_{1}(t)+\cdots+D_{J-2}(t)+D_{J-1}(t)+D_{J}(t)+S_{J}(t)
$$

where $D_{j}=\sum_{k} d_{J, k} \psi_{J, k}(t)$ and $S_{J}=\sum_{k} S_{J, k} \phi_{J, k}(t)$ with $j=1, \ldots, J$.. The detailed $D_{j}$ parameters provide the increments at each resolution level while the parameter, $S_{J}$, represents the smooth long-term component (Ramsey, 2014).

In order to obtain wavelet coefficients, the stationary observations are decomposed into several wavelet scales applying the MODWT with the Daubechies [LA(8)] wavelet filter through the R package waveslim introduced by Whitcher (2005). For our study, the MODWT is preferred four this study instead of DWT since, as noted by Percival and Mofjeld (1997), it can handle any sample size, i.e., whether the sample size is dyadic or not, it is translation-invariance, it offers more asymptotically efficient wavelet variance estimator and increased resolution at higher scales due to oversampling the data. The achievable level of MODWT is $9 \leq \log _{2}(604)$, but the optimal integer decomposition level for the study is determined as $J=5$ since the number of feasible, non-boundary effected, wavelet coefficients decline gradually as scale increases. It should be firmly noted that the multiresolution coefficients generated by the MODWT MRA function are equal to the sample size at each decomposition level. With the periodic boundary condition, it provides five levels of detail components $\mathrm{d} 1+\mathrm{d} 2+\mathrm{d} 3+\mathrm{d} 4+\mathrm{d} 5$ and one smooth component $\mathrm{s} 5$ for MODWT MRA and five levels of wavelet components $w 1+w 2+w 3+w 4+w 5$ and one scaling component s5 for MODWT. They are corresponding to [2-4) weeks for d1 (w1), [4-8) weeks for d2, [8-16) weeks for d3, [16-32) weeks for d4, [32-64) weeks for d5, and [64<) weeks for $\mathrm{s} 5$.

\subsection{Breitung and Candelon (2006) Frequency Causality Test}

The papers of Granger (1969), Geweke (1982), and Hosoya (1991) are among the pioneers to study the causal relation in the frequency-domain in the last century. Building on these papers, Breitung and Candelon (2006) developed a frequency-domain causality test based on 
imposing linear restrictions on the parameters of the bivariate vector autoregressive (VAR) model.
Let $z_{t}=\left[x_{t}, y_{t}\right]^{\prime}$ be a two-dimensional vector of data and $=1,2,3, \ldots, T$. It is also assumed that $z_{t}$ has a finite-order VAR representation of the following form

$$
\Theta(L) z_{t}=\epsilon_{t} \& \Theta(L)=I-\Theta_{1} L-\Theta_{2} L^{2}-\cdots-\Theta_{S} L^{S}
$$

where $\Theta(L)$ in Equation (3) is a $2 \times 2$ lag polynomial with the condition of $L^{k} z_{t}=z_{t-k}$. Additionally, the error vector $\epsilon_{t}$ is supposed to be white noise with $E\left(\epsilon_{t}\right)=0$ and $E\left(\epsilon_{t} \epsilon_{t}^{\prime}\right)=\Sigma$, where $\Sigma$ is positive definite.
The linear measure of frequency-based causality relationship at frequency point $(\omega)$ as proposed by Geweke (1982) and Hosoya (1991) can be defined as

$$
M_{x \rightarrow y}(\omega)=\log \left[\frac{2 \pi f_{X}(\omega)}{\left|\mathcal{F}_{11}\left(e^{-i \omega}\right)\right|^{2}}\right]=\log \left[1+\frac{\left|\mathcal{F}_{12}\left(e^{-i \omega}\right)\right|^{2}}{\left|\mathcal{F}_{11}\left(e^{-i \omega}\right)\right|^{2}}\right]
$$

where $M_{x \rightarrow y}(\omega)$ and $f_{X}(\omega)$ is a sign of the causality at a frequency $(\omega)$ and spectral density of $X_{t}$, respectively. If the condition of $\left|\mathcal{F}_{12}\left(e^{-i \omega}\right)\right|=0$ holds, then $M_{Y \rightarrow X}(\omega)$ measure becomes zero, namely, at frequency point of $(\omega), x_{t}$, does not cause $y_{t}$.

$$
\sum_{k=1}^{S} \Theta_{12, k} \sin (k \omega)=0 \quad \& \quad \sum_{k=1}^{S} \Theta_{12, k} \cos (k \omega)=0
$$

Next, the necessary VAR Equation for the variable, $y_{t}$, is written as

$$
y_{t}=\mu_{1} y_{t-1}+\cdots+\mu_{k} y_{t-k}+b_{1} x_{t-1}+\cdots+b_{k} x_{t-k}+\epsilon_{1 t}
$$

Holding the following conditions

$$
\begin{aligned}
& b=\left[b_{1}, b_{2}, \ldots, b_{k}\right]^{\prime} \\
& M(\omega)=\left[\begin{array}{llllll}
\cos (\omega) & \cos (2 \omega) & \cos (3 \omega) & \cos (4 \omega) & \ldots & \cos (k \omega) \\
\sin (\omega) & \sin (2 \omega) & \sin (3 \omega) & \sin (4 \omega) & \ldots & \sin (k \omega)
\end{array}\right]
\end{aligned}
$$

Then, the null hypothesis $M_{x \rightarrow y}(\omega)=0$ being equal to the linear restriction can be described as

$$
H_{0}: M(\omega) b=0
$$

For the linear restrictions entailed by Equation (7), the authors (2006) assert that the null hypothesis of non-causality at $(\omega)$ point is tested by employing a standard $F$ test approximately distributed as $F(2, N-2 k)$ for $\omega \in(0, \pi)$ for .

\subsection{Data}

Our data consist of Turkey two-year government bond yields (TR2YGB) and the aggregate stock market (Bist100, XU100); the financials (BIST Financials, XUMAL, BIST Banks, XBANK, BIST Leasing \& Factoring, XFINK, BIST Real Estate Investments Trusts, XGMYO, BIST Holding and Investment, XHOLD, and BIST Insurance, XSGRT); the industrials (BIST Industrials, XUSIN, BIST Food Beverage, XGIDA, BIST Wood Paper Printing, XKAGT, BIST Chemical Petrol Plastic, XKMYA, BIST Basic Metal, XMANA, BIST Metal Products Machinery, XMESY, BIST Nonmetal Min. Product, XTAST, and BIST Textile 
Leather, XTEKS); the services (BIST Services, XUHIZ, BIST Electricity, XELKT, BIST Telecommunication, XILTM, BIST Sports, XSPOR, BIST Wholesale and Retail Trade, XTCRT, BIST Tourism, XTRZM, BIST Transportation, XULAS), the technology (BIST Technology, XUTEK and BIST Inf. Technology, XBLSM), and the BIST Investment Trust (XYORT) indices. The data on prices for the sample period was obtained from the CBRT Bloomberg Terminal and the Borsa Istanbul A.Ş database, EVDS, and the sample period starts in the $1^{\text {st }}$ week of April 2005 and ends in the $4^{\text {th }}$ week of December 2016, with a total of 605 observations.

For our analysis, all variables are converted into natural logarithms to remedy potential heteroskedasticity problems. The weekly continuously compounded returns are calculated as $r_{t}=\log \left(F_{t} / F_{t-1}\right)$ where $F_{t}$ is the weekly closing price. Table 1 reveals the summary statistics results for the underlying data.

Table 1: Descriptive Statistic for Return Series

\begin{tabular}{|c|c|c|c|c|c|c|c|c|}
\hline Variables & Mean & SD & Min & Max & Skewness & Kurtosis & $J B$ & $\mathrm{n}$ \\
\hline RTR2YGB & -0.0010 & 0.0339 & -0.1361 & 0.1953 & 0.7012 & 6.9793 & $447.99^{* * *}$ & 604 \\
\hline RXU100 & 0.0018 & 0.0380 & -0.1927 & 0.1576 & -0.4538 & 5.1638 & $138.56^{* * *}$ & 604 \\
\hline RXUMAL & 0.0017 & 0.0447 & -0.2169 & 0.2035 & -0.3100 & 5.1215 & $122.94^{* * *}$ & 604 \\
\hline RXBANK & 0.0017 & 0.0487 & -0.2059 & 0.2151 & -0.1724 & 4.6049 & $67.81^{* * *}$ & 604 \\
\hline RXFINK & 0.0021 & 0.0463 & -0.3598 & 0.2466 & -0.7402 & 12.3350 & $2248.23^{* * *}$ & 604 \\
\hline RXGMYO & 0.0008 & 0.0382 & -0.1955 & 0.1109 & -0.9653 & 5.8977 & $305.10^{* * *}$ & 604 \\
\hline RXHOLD & 0.0015 & 0.0420 & -0.2450 & 0.1967 & -0.5723 & 6.4615 & $334.52^{* * *}$ & 604 \\
\hline RXSGRT & 0.0025 & 0.0438 & -0.2885 & 0.1648 & -1.0315 & 8.9631 & $1001.97^{* * *}$ & 604 \\
\hline RXUSIN & 0.0022 & 0.0328 & -0.2012 & 0.1182 & -1.0299 & 6.8019 & $470.54^{* * *}$ & 604 \\
\hline RXGIDA & 0.0022 & 0.0375 & -0.1720 & 0.1201 & -0.3345 & 4.9350 & $105.49^{* * *}$ & 604 \\
\hline RXKAGT & 0.0010 & 0.0388 & -0.2297 & 0.1343 & -0.5219 & 5.8779 & $235.86^{* * *}$ & 604 \\
\hline RXKMYA & 0.0024 & 0.0385 & -0.1772 & 0.1616 & -0.4629 & 5.1143 & $134.07^{* * *}$ & 604 \\
\hline RXMANA & 0.0028 & 0.0471 & -0.2442 & 0.2092 & -0.6311 & 6.0115 & $268.34^{* * *}$ & 604 \\
\hline RXMESY & 0.0026 & 0.0398 & -0.2664 & 0.1462 & -1.0675 & 7.8306 & $701.96^{* * *}$ & 604 \\
\hline RXTAST & 0.0016 & 0.0316 & -0.1592 & 0.1128 & -0.7356 & 4.9985 & $154.99^{* * *}$ & 604 \\
\hline RXTEKS & 0.0020 & 0.0360 & -0.2255 & 0.1102 & -0.9645 & 6.8707 & $470.69^{* * *}$ & 604 \\
\hline RXUHIZ & 0.0021 & 0.0305 & -0.1310 & 0.1573 & -0.3166 & 4.9074 & $101.64^{* * *}$ & 604 \\
\hline RXELKT & 0.0004 & 0.0491 & -0.3515 & 0.3541 & -0.3333 & 12.2637 & $2170.90^{* * *}$ & 604 \\
\hline RXILTM & 0.0008 & 0.0397 & -0.1422 & 0.1426 & -0.1267 & 3.9193 & $22.88^{* * *}$ & 604 \\
\hline RXSPOR & 0.0014 & 0.0509 & -0.4580 & 0.2246 & -1.0546 & 16.3996 & $4630.60^{* * *}$ & 604 \\
\hline RXTCRT & 0.0036 & 0.0369 & -0.2351 & 0.2793 & -0.0189 & 10.9406 & $1586.87^{* * *}$ & 604 \\
\hline RXTRZM & 0.0003 & 0.0480 & -0.2237 & 0.1844 & -0.4723 & 5.4039 & $167.89^{* * *}$ & 604 \\
\hline RXULAS & 0.0028 & 0.0524 & -0.2973 & 0.2029 & -0.4437 & 5.6122 & $191.53^{* * *}$ & 604 \\
\hline RXUTEK & 0.0032 & 0.0400 & -0.1958 & 0.1345 & -0.6553 & 5.0615 & $150.17^{* * *}$ & 604 \\
\hline RXBLSM & 0.0020 & 0.0421 & -0.1875 & 0.1786 & -0.4018 & 5.9064 & $228.83^{* * *}$ & 604 \\
\hline RXYORT & 0.0007 & 0.0317 & -0.1923 & 0.0950 & -1.1748 & 7.7277 & $701.44^{* * *}$ & 604 \\
\hline
\end{tabular}

***,**, and ${ }^{*}$ signify $1 \%, 5 \%$, and $10 \%$ significance levels, respectively. 
Table 2: The Lee and Strazicich (2003) Unit Root Test Results

\begin{tabular}{|c|c|c|c|c|c|c|c|c|c|}
\hline \multirow{2}{*}{ Variable } & \multicolumn{4}{|c|}{ Model A } & \multirow{2}{*}{ Variable } & \multicolumn{4}{|c|}{ Model C } \\
\hline & LM test & Lag & BP1 & BP2 & & LM test & Lag & BP1 & BP2 \\
\hline LTR2YGB & -2.3437 & 5 & $2009-12-31$ & 2013-05-24 & LTR2YGB & -4.2394 & 12 & 2009-06-12 & 2013-09-13 \\
\hline LXU100 & -3.1904 & 17 & $2007-12-28$ & 2009-11-25 & LXU100 & -5.0486 & 17 & 2008-08-08 & $2009-11-25$ \\
\hline LXUMAL & -3.1054 & 17 & 2008-05-16 & $2009-11-25$ & LXUMAL & -4.9351 & 17 & 2008-08-08 & $2009-11-25$ \\
\hline LXBANK & -3.1023 & 17 & 2008-11-21 & 2014-09-05 & LXBANK & -4.7853 & 17 & $2008-07-25$ & $2009-11-25$ \\
\hline LXFINK & -2.5776 & 16 & 2007-08-10 & 2009-02-13 & LXFINK & -4.3673 & 16 & 2008-05-02 & 2010-04-16 \\
\hline LXGMYO & -2.7537 & 11 & 2009-01-16 & 2010-05-07 & LXGMYO & $-5.4543^{*}$ & 17 & 2008-08-08 & 2009-12-31 \\
\hline LXHOLD & -3.0897 & 15 & 2007-08-10 & 2009-02-06 & LXHOLD & -4.9003 & 15 & $2008-07-25$ & 2009-10-02 \\
\hline LXSGRT & -2.9718 & 14 & 2008-05-02 & 2009-10-23 & LXSGRT & -5.1396 & 14 & 2008-05-02 & 2009-09-04 \\
\hline LXUSIN & -3.4393 & 15 & 2008-01-11 & 2009-03-06 & LXUSIN & $-5.5427^{*}$ & 15 & 2008-08-08 & $2009-11-25$ \\
\hline LXGIDA & -2.4913 & 17 & 2008-10-10 & 2015-07-15 & LXGIDA & -4.5719 & 17 & 2008-10-10 & 2013-05-31 \\
\hline LXKAGT & -3.0025 & 17 & $2007-02-23$ & 2012-01-20 & LXKAGT & -4.6471 & 17 & 2008-08-01 & 2012-12-07 \\
\hline LXKMYA & $-3.5965^{*}$ & 15 & 2008-01-11 & 2009-03-06 & LXKMYA & $-5.3102^{*}$ & 17 & 2008-08-08 & $2009-12-31$ \\
\hline LXMANA & -3.4763 & 13 & 2009-03-06 & 2011-11-18 & LXMANA & -4.9679 & 17 & 2007-06-01 & $2008-10-24$ \\
\hline LXMESY & -2.8542 & 15 & 2007-08-10 & 2009-02-06 & LXMESY & $-6.488^{* * *}$ & 17 & 2008-08-01 & 2009-10-02 \\
\hline LXTAST & -2.4616 & 15 & 2009-02-13 & $2013-12-20$ & LXTAST & -4.0229 & 15 & 2008-05-02 & $2010-01-22$ \\
\hline LXTEKS & -2.5865 & 15 & 2010-05-07 & 2011-08-19 & LXTEKS & -5.0309 & 15 & 2008-08-01 & 2011-01-14 \\
\hline LXUHIZ & -2.8762 & 17 & 2008-11-21 & 2015-03-06 & LXUHIZ & -3.8998 & 15 & 2008-07-25 & $2013-01-25$ \\
\hline LXELKT & $-3.7587^{*}$ & 14 & 2008-11-21 & 2011-11-18 & LXELKT & -4.7971 & 13 & 2009-07-24 & $2011-11-18$ \\
\hline LXILTM & $-3.9727^{* *}$ & 1 & 2007-09-28 & 2015-04-03 & LXILTM & $-5.6186^{*}$ & 0 & 2008-05-02 & 2014-12-05 \\
\hline LXSPOR & -1.6754 & 16 & 2008-06-27 & 2012-05-11 & LXSPOR & -4.2604 & 15 & 2010-08-20 & 2013-09-13 \\
\hline LXTCRT & -3.0529 & 14 & 2008-11-21 & 2010-05-07 & LXTCRT & -4.4331 & 17 & 2008-09-26 & $2010-04-30$ \\
\hline LXTRZM & -2.6056 & 15 & 2009-02-06 & 2011-11-18 & LXTRZM & -3.7178 & 15 & 2007-07-06 & 2009-10-02 \\
\hline LXULAS & -2.2568 & 15 & 2008-07-25 & $2012-01-27$ & LXULAS & -3.4186 & 15 & 2009-07-03 & $2015-10-30$ \\
\hline LXUTEK & -2.2573 & 18 & $2007-02-23$ & 2013-09-13 & LXUTEK & -4.4592 & 18 & 2008-05-09 & 2009-12-31 \\
\hline LXBLSM & -2.4369 & 18 & 2007-06-01 & 2009-02-20 & LXBLSM & -3.4794 & 18 & 2008-05-02 & $2010-01-22$ \\
\hline LXYORT & -2.6979 & 17 & 2007-06-01 & $2010-02-26$ & LXYORT & -4.9629 & 17 & $2008-05-16$ & $2010-01-22$ \\
\hline
\end{tabular}

$*^{* *},{ }^{* *}$, and * signify 1\%, 5\%, and 10\% significance level, respectively. BP1 and BP2 denote the first and the second breakpoint.

The weekly mean growth rate for the stock indices was positive while it was negative for the benchmark government bond rates, indicating a poor performance for the bonds. The average stock return varied between -0.2318 and 0.1744 , while the growth rate for bond varied between -0.161 and 0.1953 , with a standard deviation of 0.0410 and 0.0339 , respectively. This result suggested that investors were not compensated for a higher risk premium when holding stock instruments in Turkey. During the same period, the stock indices that experienced the highest (0.3541) and lowest $(-0.4580)$ weekly return was RXELKT and RXSPOR, with a standard deviation of $4.91 \%$ and $5.09 \%$. The third moment indicates that the distributions of all of the stock returns were negatively skewed while the distribution of the interest rate changes, [0.7012], was positively skewed. Furthermore, the fourth moment specifies that the distributions of all of the financial variables showed a leptokurtic behavior; that is, they had fat tails and peakedness. Those and the Jarque-Bera test findings, therefore, reveal no normality in the data at a $1 \%$ significance level.

\section{Findings and Discussions}

\subsection{Empirical Results}

Non-stationarity of time series is a critical and primary pre-condition before testing cointegration and causal relationship between variables. As suggested, we use both the conventional and modern unit root tests to explore non-stationarity. For brevity, however, we report only the non-stationarity test results employing the Lee and Strazicich (2003) method, as given in Table 2. Our empirical evidence shows that only three out of twenty-six variables, LXKMYA, LXELKT, and LXILTM, are stationary for Model A and five variables, LXGMYO, 
LXUSIN, LXKMYA, LXMESY, and LXILTM, are I(0) at log-level for Model $C$. All variables are integrated of the first order, i.e., I(1) using both unit root test approaches.

Table 3 reports the empirical findings of the cointegration tests with two endogenous breaks, proposed by Hatemi-J (2008), for all combinations that include nonstationary variables, $I(1)$. It is quite apparent that the null hypothesis of no cointegration could be only rejected for five out of nineteen models when the log of equity price is treated as an explained variable. Since their critical values are at least lower than the critical value, -5.653 at a $10 \%$ level of significance, LGB2 has long-run relationships with LXUMAL, LXHOLD, LXTEKS, LXTRZM, and LXULAS, implying that the government bond rate move in tandem with those indices in the long-term. However, this test is unable to reject the null hypothesis for the reverse cointegration relation for all combinations except for the LGB2 LXUHIZ model at a $10 \%$ level of significance, suggesting only one signifi- cant relationship for the dependent variable, LGB2. It is noteworthy also that the structural breaks selected by the Hatemi-J (2008) approach are corresponding to the recent global and the eurozone crisis.

Table 4 illustrates the short- and long-run causality test results. As shown, there is only one significant causal link running from the interest rate, LTR2YGB, to the equity prices, LXHOLD, in the short-run. When looking at the second column, the null hypothesis of no causation relationship cannot be accepted for all models in the long term, suggesting that interest rates are found to exert significant lagged impacts on LXUMAL, LXHOLD, LXTEKS, and LXULAS indices and LXTRZM at $1 \%$ and $5 \%$ significance level, respectively. Conversely, the speed of the adjustment, $E C T_{t-1}$, parameter reveals that the disequilibrium between variables is corrected in 27.8 [ $=1 /-0.036]$ weeks for LXUMAL; 52.6 weeks for LXHOLD; 58.8 weeks for LXTEKS; 76.9 weeks for LXTRZM and 90.9 weeks for LXULAS sector indices.

Table 3: Hatemi-J (2008) Cointegration Test

\begin{tabular}{|c|c|c|c|c|c|c|c|c|c|c|c|}
\hline \multirow{2}{*}{ Model } & & & \multicolumn{3}{|c|}{ Modified ADF Test [C/S Model] } & \multirow{2}{*}{\multicolumn{3}{|c|}{ Model }} & \multicolumn{3}{|c|}{ Modified ADF Test [C/S Model] } \\
\hline & & & \multirow{2}{*}{$\begin{array}{l}\text { Stat } \\
5.25\end{array}$} & \multirow{2}{*}{\begin{tabular}{|l|} 
BP1 \\
$2008-08-29$
\end{tabular}} & \multirow{2}{*}{\begin{tabular}{|l} 
BP2 \\
$2012-01-06$
\end{tabular}} & & & & \multirow{2}{*}{\begin{tabular}{|l|} 
Stat \\
4.87
\end{tabular}} & \multirow{2}{*}{\begin{tabular}{|l} 
BP1 \\
$2008-09-26$
\end{tabular}} & \multirow{2}{*}{$\begin{array}{l}\text { BP2 } \\
2011-11-04\end{array}$} \\
\hline LXU100 & $\sim$ & LGB2 & & & & GB2 & $\sim$ & LXU100 & & & \\
\hline LXUMAL & $\sim$ & LGB2 & $-5.75^{*}$ & 2008-08-29 & 2010-08-06 & LGB2 & $\sim$ & LXUMAL & -4.76 & 2008-08-08 & $2011-12-23$ \\
\hline LXBANK & $\sim$ & LGB2 & -5.54 & 2008-08-29 & 2010-08-13 & LGB2 & $\sim$ & LXBANK & -4.54 & 2008-09-26 & $2011-11-25$ \\
\hline LXFINK & $\sim$ & LGB2 & -5.37 & $2008-05-23$ & 2008-10-03 & LGB2 & $\sim$ & LXFINK & -4.38 & 2008-06-20 & 2013-01-11 \\
\hline LXGMYO & $\sim$ & LGB2 & NA & & & LGB2 & $\sim$ & LXGMYO & NA & & \\
\hline LXHOLD & $\sim$ & LGB2 & $-5.84^{*}$ & 2008-08-29 & 2011-12-02 & LGB2 & $\sim$ & LXHOLD & -5.07 & 2008-08-15 & $2011-12-16$ \\
\hline LXSGRT & $\sim$ & LGB2 & -5.37 & 2008-08-29 & 2011-01-07 & LGB2 & $\sim$ & LXSGRT & -5.31 & 2008-09-19 & 2011-07-29 \\
\hline LXUSIN & $\sim$ & LGB2 & NA & & & LGB2 & $\sim$ & LXUSIN & NA & & \\
\hline LXGIDA & $\sim$ & LGB2 & -4.84 & 2008-11-28 & 2010-02-05 & LGB2 & $\sim$ & LXGIDA & -4.94 & 2009-05-08 & 2011-11-11 \\
\hline LXKAGT & $\sim$ & LGB2 & -5.41 & 2008-10-17 & 2010-07-30 & LGB2 & $\sim$ & LXKAGT & -5.39 & 2009-02-13 & 2011-11-04 \\
\hline LXKMYA & $\sim$ & LGB2 & NA & & & LGB2 & $\sim$ & LXKMYA & NA & & \\
\hline LXMANA & $\sim$ & LGB2 & -4.35 & 2007-04-20 & $2012-04-27$ & LGB2 & $\sim$ & LXMANA & -5.01 & 2009-05-08 & 2011-12-09 \\
\hline LXMESY & $\sim$ & LGB2 & NA & & & LGB2 & $\sim$ & LXMESY & NA & & \\
\hline LXTAST & $\sim$ & LGB2 & -5.36 & 2008-08-01 & 2008-08-08 & LGB2 & $\sim$ & LXTAST & -4.39 & 2008-06-20 & 2013-01-25 \\
\hline LXTEKS & $\sim$ & LGB2 & $-5.77^{*}$ & 2008-06-13 & 2008-10-31 & LGB2 & $\sim$ & LXTEKS & -4.51 & 2009-05-08 & 2011-12-09 \\
\hline LXUHIZ & $\sim$ & LGB2 & -4.95 & 2007-02-09 & 2011-11-04 & LGB2 & $\sim$ & LXUHIZ & $-5.66^{*}$ & 2009-05-15 & 2011-11-04 \\
\hline LXELKT & $\sim$ & LGB2 & NA & & & LGB2 & $\sim$ & LXELKT & NA & & \\
\hline LXILTM & $\sim$ & LGB2 & NA & & & LGB2 & $\sim$ & LXILTM & NA & & \\
\hline LXSPOR & $\sim$ & LGB2 & -4.23 & 2008-01-04 & 2010-09-03 & LGB2 & $\sim$ & LXSPOR & -4.81 & 2009-06-12 & $2011-11-25$ \\
\hline LXTCRT & $\sim$ & LGB2 & -4.93 & 2008-12-05 & 2011-11-04 & LGB2 & $\sim$ & LXTCRT & -5.38 & 2009-04-24 & $2011-11-25$ \\
\hline LXTRZM & $\sim$ & LGB2 & $-6.42^{* *}$ & 2008-06-13 & 2010-02-05 & LGB2 & $\sim$ & LXTRZM & -4.83 & 2009-06-12 & $2011-11-25$ \\
\hline LXULAS & $\sim$ & LGB2 & $-5.8^{*}$ & 2008-08-08 & 2011-10-27 & LGB2 & $\sim$ & LXULAS & -5.57 & 2009-04-24 & $2011-11-25$ \\
\hline LXUTEK & $\sim$ & LGB2 & -4.2 & 2008-10-24 & 2012-05-18 & LGB2 & $\sim$ & LXUTEK & -4.92 & 2008-09-12 & $2011-11-25$ \\
\hline LXBLSM & $\sim$ & LGB2 & -3.92 & 2008-08-01 & 2013-01-25 & LGB2 & $\sim$ & LXBLSM & -4.59 & 2008-09-12 & 2009-06-05 \\
\hline LXYORT & $\sim$ & LGB2 & -5.35 & 2008-03-07 & $2010-02-26$ & LGB2 & $\sim$ & LXYORT & -5.22 & 2008-10-03 & 2011-12-09 \\
\hline
\end{tabular}

******, and * signify $1 \%, 5 \%$, and $10 \%$ significance level, respectively. BP1 and BP2 denote the first and the second breakpoint. 
Table 5 reports the empirical findings of the symmetric causality test of Hacker and Hatemi-J (2006), using raw returns and decomposed series. We find that the causality seems to be running from RTR2YGB to stock returns, with the exceptions for RXKAGT, RXILTM, RXSPOR, RXULAS, and RXUTEK, and not the other way around in the time domain. Applying this approach to the decomposed series, the null hypothesis that RTR2YGB does not lead the share returns cannot be accepted at scale $\mathrm{d} 3$ for only RXHOLD, RXGIDA, RXMESY, and RXBLSM. However, regarding the causal relation from equity returns to interest rate fluctuations, the findings are not significant for any cases in the time domain. Using the wavelets, we found that the dynamic causal relations intensify over time for some stock returns beyond the second-level time scale. For example, RTR2YGB is Granger-caused by RXU100, RXHOLD, RXSGRT, RXKMYA, and RXTCRT at scale $\mathrm{d} 3$ and d5 scales, by RXKAGT and RXTRZM at scale $\mathrm{d} 2$ and $\mathrm{d} 3$, [4-16) week periods.

Table 6 reports the findings of the asymmetric causality test of Hatemi-J (2012). The left side presents the positive and the negative shocks of interest rates to stock prices during the period. Unsurprisingly, there are high strengths of Granger-causality running from the positive shocks in interest rates, LTR2YGB, to the negative shocks in stock prices, LXELKT and LXMESY at 10\%; LXU100, LXUMAL, LXBANK, LXHOLD, and LXULAS at $5 \%$ and $L X M A N A$ at $1 \%$ significance level. Further, the negative shocks of LTR2YGB are found to exert significant lagged influences on the positive shocks in LXFINK and LXKAGT. Our paper also suggests that there exist significant causal links between the same components; for instance, the predictability of the positive (negative) shocks in LXTRZM can be improved through using the positive (negative) shocks in LTR2YGB at significance level in the short-run. It can be concluded that the impact of shocks stemming from LTR2YGB on stock prices is less pronounced for our paper.

The right side of Table 6 shows the effects of shocks arising from stock prices on interest rates. Our findings demonstrate that the null hypothesis that the shocks in equity price, LXSGRT, do not lead the interest rate shocks in LTR2YGB could be rejected for all the combinations of cumulative price shocks. The decreasing stock prices, LXU100, cause both the falling and increasing bond yields, LTR2YGB, namely, interest rates in Turkey negatively and positively respond to stock price decreases, suggesting that falling stock price is regarded by the bond market participants as a negative and affirmative signal. Similarly, the falling stock prices of LXUMAL, LXBANK, LXHOLD, LXKMYA, and LXULAS can be perceived as a negative and positive impact on interest rates. As noted by Hatemi-J (2012), the possibility of reaching systematic opportunities for excess yields from the stock prices, excluding LXMANA, LXUHIZ, LXELKT, and LXILTM, is ruled out in the bond market.

Table 4: Standard Granger Causality - VECM

\begin{tabular}{|c|c|c|c|c|}
\hline \multirow[t]{2}{*}{ Dependent } & \multirow[t]{2}{*}{$\sim$} & \multirow[t]{2}{*}{ Independent } & \multicolumn{2}{|c|}{ LTR2YGB $\nRightarrow L X$} \\
\hline & & & $\begin{array}{c}\chi^{2} \\
\text { statistics[Short] }\end{array}$ & $E C T_{t-1}[$ Long] \\
\hline LXUMAL & $\sim$ & LTR2YGB & 0.96 & $-0.036^{* * *}$ \\
\hline LXHOLD & $\sim$ & LTR2YGB & $6.806^{*}$ & $-0.019^{* * *}$ \\
\hline LXTEKS & $\sim$ & LTR2YGB & 0.619 & $-0.017^{* * *}$ \\
\hline LXTRZM & $\sim$ & LTR2YGB & 0.553 & $-0.014^{* *}$ \\
\hline LXULAS & $\sim$ & LTR2YGB & 3.083 & $-0.012^{* * *}$ \\
\hline LTR2YGB & $\sim$ & LXUHIZ & 0.505 & -0.001 \\
\hline
\end{tabular}

$*^{* * *}$, ${ }^{* *}$, and ${ }^{*}$ signify $1 \%, 5 \%$, and $10 \%$ significance level, respectively. 


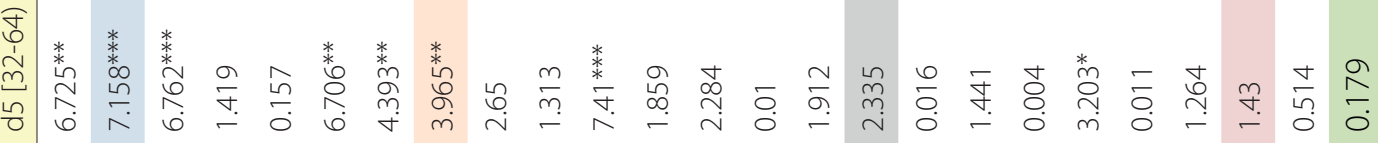

$\underset{\sim}{\approx}$

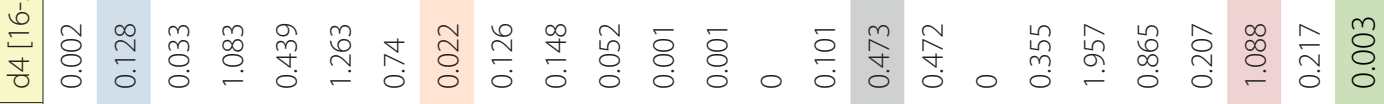

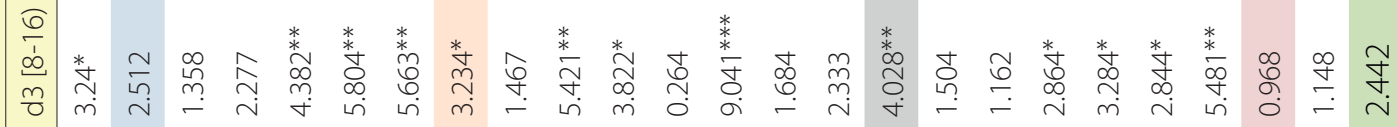

ֻึ

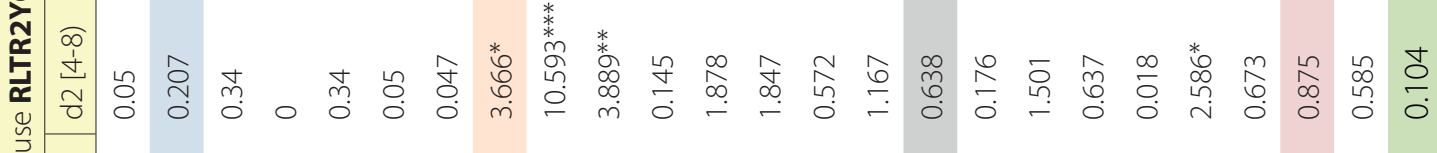

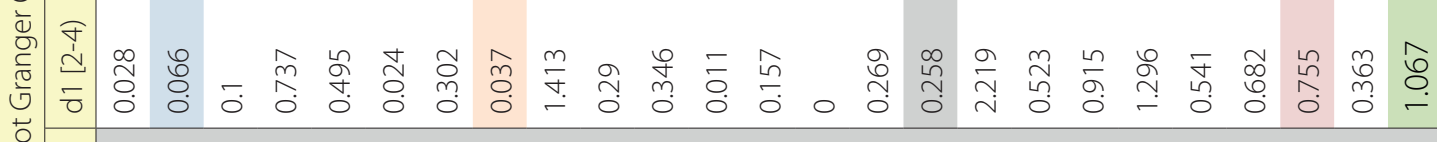

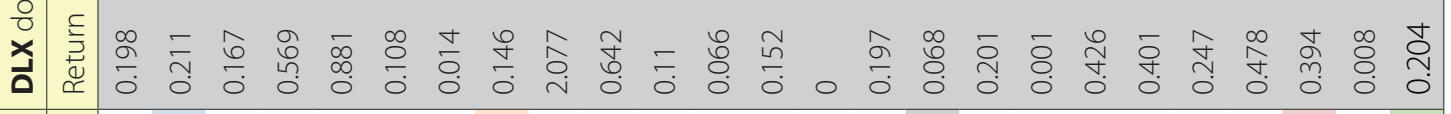

శ্ণী

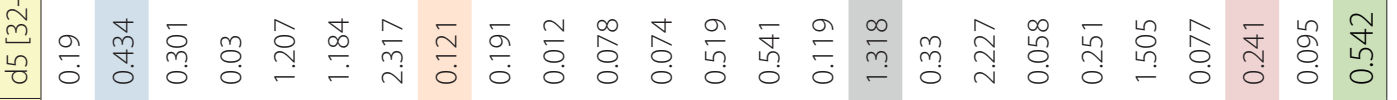

$\frac{0}{\sqrt{0}}$

入

శิ

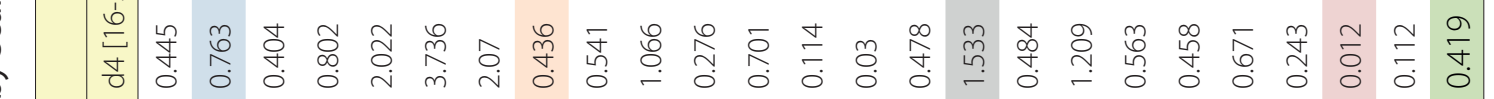

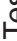

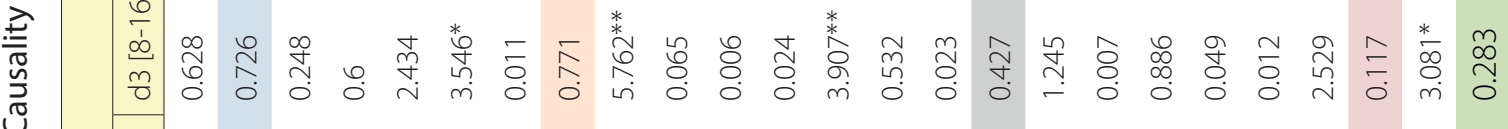

崌



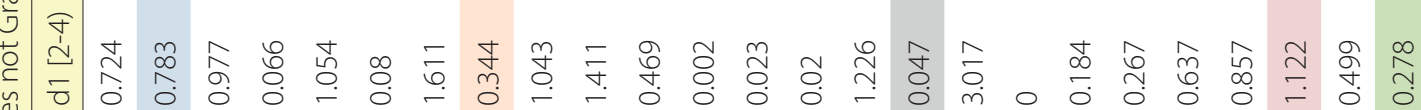

号

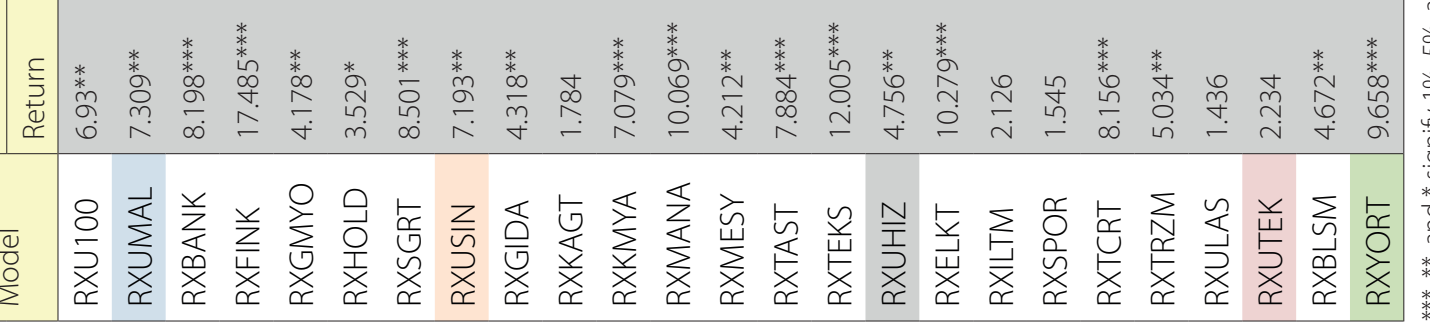




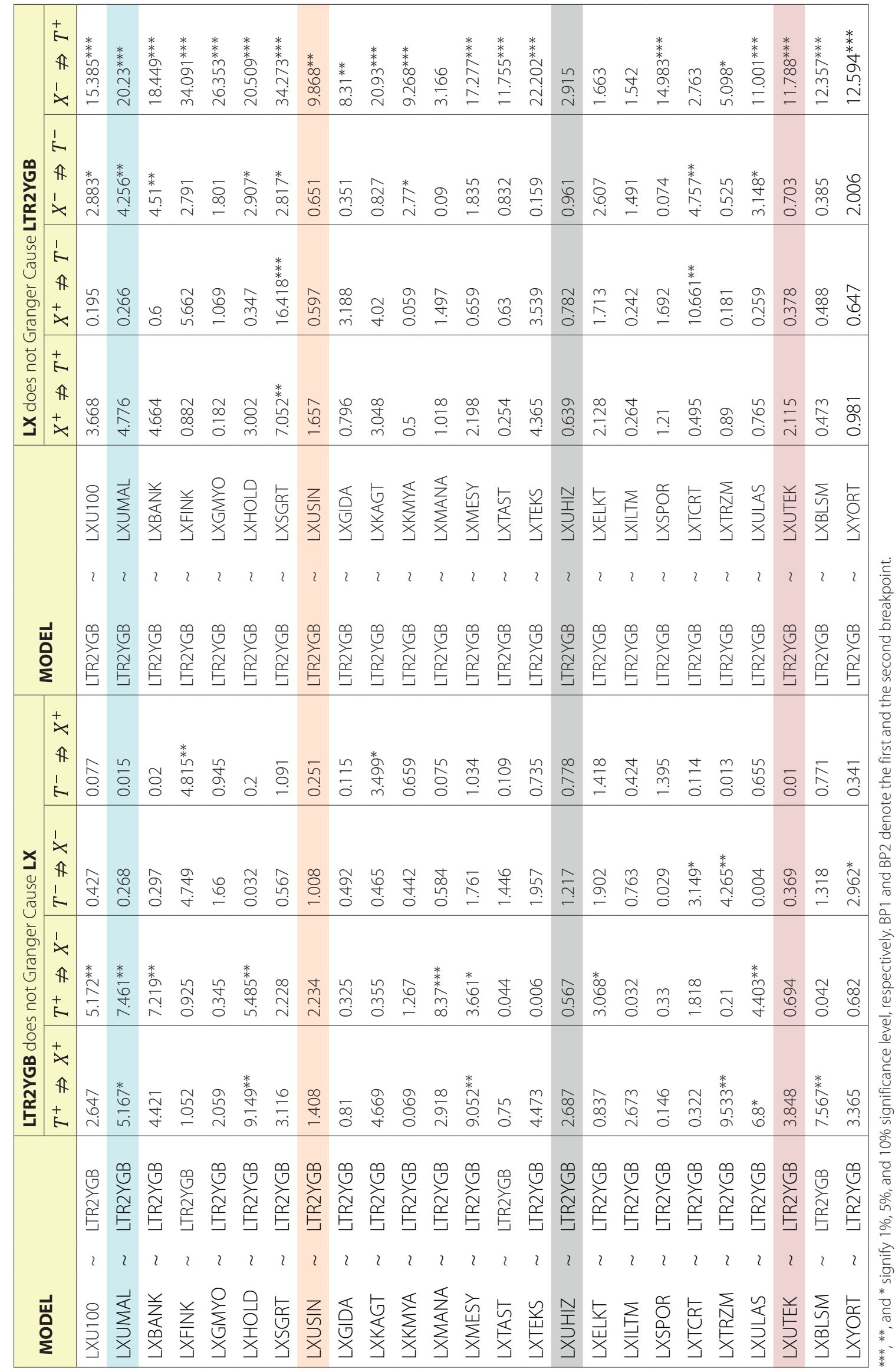



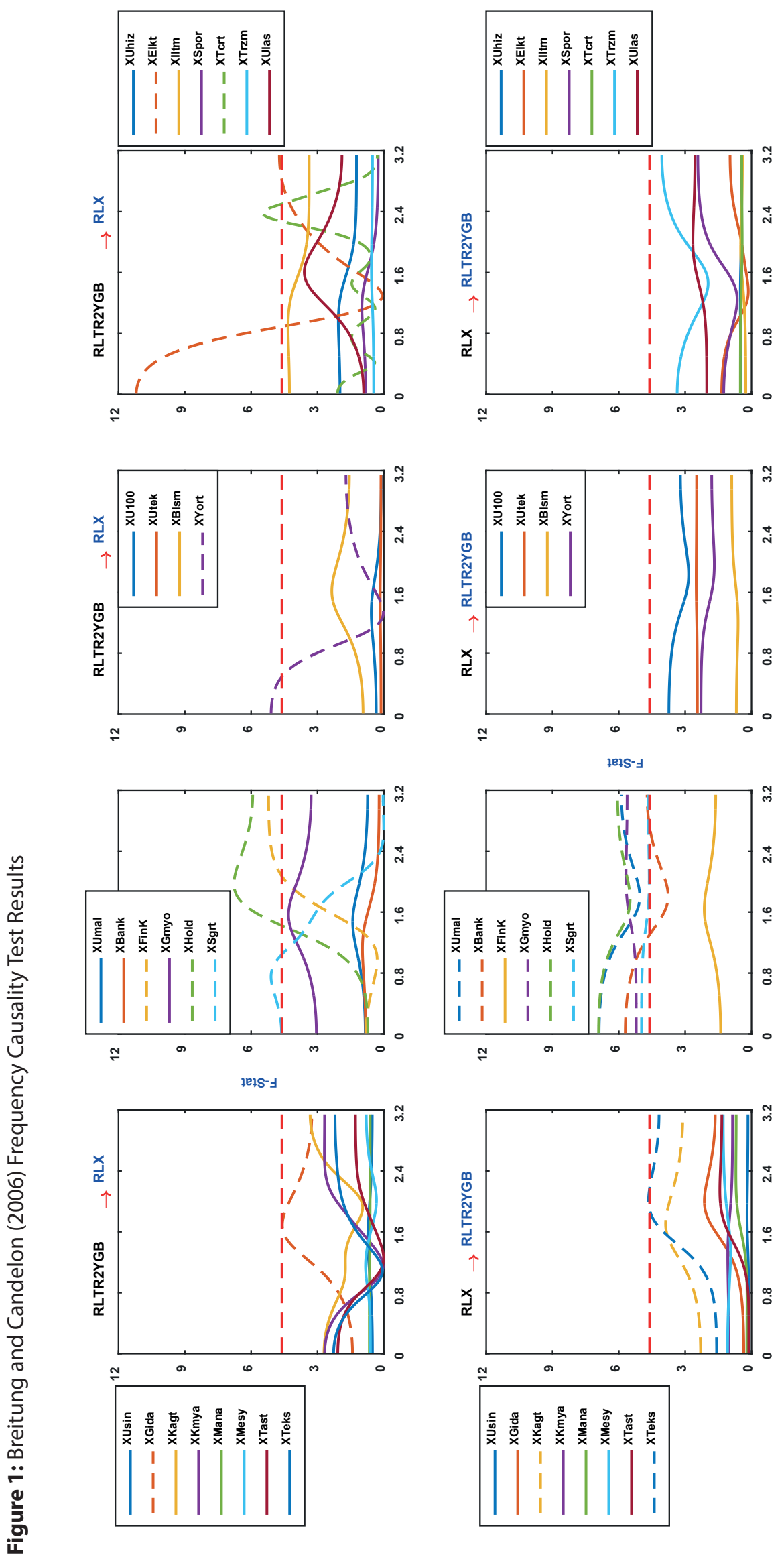
We present the frequency domain causality test, proposed by Breitung and Candelon (2006) results in Figure 1. The upper panel illustrates the causality from innovations in interest rates to stock index returns, and the bottom depicts the relationship in the reverse direction. The RXHOLD and RXSGRT indices are the two variables that have bidirectional causalities with the RTR2YGB in the underlying period at different frequency intervals.

The figure shows that there exist significant causal relations running from RTR2YGB to RXELKT at $[0.01 \leq \omega \leq 0.89$ and $2.82 \leq \omega \leq 3.14$, RXFINK at [2.07 $\leq \omega \leq 3.14]$, RXTCRT at [2.28 $\leq \omega \leq 2.50]$, and RXYORT at $[0.01 \leq \omega \leq 0.49]$ frequency intervals. At the bottom panel, the RXUMAL, RXGMYO, and RXHOLD appear to Granger-cause the RTR2YGB at all the levels of frequencies, $[0.01 \leq \omega \leq 3.14]$, reflecting short-, intermediate-, and long-run cycles. Moreover, there is disputed evidence on the existence of causal relations running from RXBANK to RTR2YGB at $[0.01 \leq \omega \leq 1.30$ $\& 2.72 \leq \omega \leq 3.14$ corresponding to holding periods between $4.83-628$ and $2.31-2$ weeks, suggesting that index returns can indeed predict the future movements of the bond yields while the reverse does not hold. A perusal of Figure 1 reveals that the null hypothesis of no significant causal association between RTR2YGB and the aggregate stock index, RXU100, cannot be rejected.

\subsection{Discussion}

In the paper, we find that Turkish stock markets seem to show more volatile behaviors than bond markets, concurring with the result from Moya-Martínez et al. (2015), who investigate stock-bond markets at both the aggregate and sectoral level relationships in Spain. Further, the findings purport long-run relationships between bond markets and several stock indices, implying that these markets cannot be used as a way of portfolio diversification for long-term investors, but be used for short-term investors. Our findings are partially in accordance with the empirical evidence documented in Evrim-Mandaci et al. (2011), Akbas (2013), and Yildiz (2014), suggesting that the tactical allocation strategy in managing both investment assets for portfolio diversification holds when both markets do not move in tandem in the long-run.

The results regarding causality test of Hacker and Hatemi-J (2006) show one-way causal relationship from the bond yield changes to the stock returns, suggesting that market agents may monitor changes in bond yield to predict movements stock returns as using the lagged bond yields movements is useful in predicting stock market changes in Turkey. These findings are fully consistent with the empirical evidence reported in Özer et al. (2011) and Yildiz (2014) for Turkey and partially in line with Rahman and Mustafa (1997), Erdem et al. (2005), Gan et al. (2006), Kasman et al. (2011), and Herve et al. (2011) for bidirectional causality in the time-domain. By employing wavelets, however, the study uncovers decomposed significant associations that being hidden over medium and long-term horizons from stock markets to bond markets. Our results are consistent with the findings of Özün and Çifter (2006), Çifter and Özün (2008), and Moya-Martínez et al. (2015) in the frequency domain. These authors revealed that the linkages become statistically significant and stronger at the longer horizons, suggesting abnormal return opportunities for only short-term investors.

\section{Conclusions}

In this empirical study, we aimed to reexamine the stock-bond association using weekly observations of government bond yields and industry returns from April 1, 2005, through December 30, 2016. Implementing wavelet methodology, we offer a deeper understanding of this relationship by considering both the aggregate and industry level to market participants, since each agent has a different investment period, degree of risk aversion, and reacts differently to the same information.

Test findings reveal positive weekly average returns for the stock returns and negative returns for the bond yields. Further, as expected and in common in existing literature, the stock market, i.e. the vast majority of stock indices, is found to be more volatile than the bond market, confirming the result of Moya-Martínez et al. (2015) for Spain case. On the other hand, the findings suggest the presence of cointegration and a one-way causal relationship between two markets in the longrun. The results regarding wavelets uncover the true dynamics of causal linkages and show that the two markets are significant predictors of each other in the medium and long time horizons. There is also evidence of asymmetrical causal relationships, namely, the test report a one-way causality from the negative shocks in stock prices to the positive shocks in interest rates. The frequency causality test, proposed by Breitung and Candelon (2006), reveals that the predictive power of the financial index returns on the interest rate changes intensifies across frequencies. 
The findings in our study offer some suggestions for stock and bond market participants. For investors, our test findings reveal that the relationship between variables is weak and insignificant at high frequencies, but it turns out to be significant at low frequencies, implying some form of feedback mechanism at longer periods. The absence of causal relationships at shorter horizons, however, indicates that they may consistently gain abnormal returns regardless of stock indices at high frequencies since bond and stock markets are a major driving force of each other's performance in the long-run. Our findings also show that both instruments can be used as hedging tools since they are perfect substitutes for investors for risk management, asset allocation, and portfolio management in the case of market turbulences. From the policy-making standpoint, regulators should take into account the time and frequency based relationships before implementing policy rate decisions and should be patient for their consequences to secure the resiliency and durability of the financial system. Lastly, further studies should consider the possible impacts of firm-specific and macroeconomic factors on this relationship by using wavelet coherence or nonlinear approaches. 


\section{References}

Acikalin, S., Aktas, R., \& Unal, S. (2008). Relationships between stock markets and macroeconomic variables: an empirical analysis of the Istanbul Stock Exchange. Investment Management and Financial Innovations, 5(1), 8-16.

Akbas, Y.E. (2013). Borsa getiri orani ve faiz orani arasindaki ilişkinin doğrusal olmayan yöntemlerle analizi: Türkiye örneği. Business and Economics Research Journal, 4(3), 21-40.

Aktaş, M., \& Akdağ, S. (2013). Türkiye'de ekonomik faktörlerin hisse senedi fiyatlari ile ilişkilerinin araştirilmasi. International Journal of Social Science Research, 2(1), 50-67.

Alam, Z. \& Rashid, K. (2014). Time series analysis of the relationship between macroeconomic factors and the stock market returns in Pakistan. Journal of Yaşar University, 9(36), 6361-6370.

Amata, E.O., Muturi, W., \& Mbewa, M (2016). Relationship between macro-economic variables, investor herding behavior and stock market volatility in Kenya. International Journal of Economics, Commerce and Management, 4(8), 36-54.

Andrieș, A. M., Ihnatov, I., \& Tiwari, A. K. (2014). Analyzing time-frequency relationship between interest rate, stock price and exchange rate through continuous wavelet. Economic Modelling, 41, 227-238.

Barakat, M. R., Elgazzar, S. H., \& Hanafy, K. M. (2015). Impact of macroeconomic variables on stock markets: Evidence from emerging markets. International Journal of Economics and Finance, 8(1), 195.

Bhattacharya, B., \& Mukherjee, J. (2002). The nature of the causal relationship between stock market and macroeconomic aggregates in India: An empirical analysis. In 4th annual conference on money and finance, Mumbai (pp. 401-426).

Breitung, J., \& Candelon, B. (2006). Testing for short-and long run causality: A frequency-domain approach. Journal of Econometrics, 132(2), 363-378.

Campbell, J. Y. (1987). Stock returns and the term structure. Journal of financial economics, 18(2), 373-399.

Chan, K. C., Norrbin, S. C., \& Lai, P. (1997). Are stock and bond prices collinear in the long run? International Review of Economics and Finance, 6(2), 193-201.

Chia, R. C. J., \& Lim, S. Y. (2015). Malaysian stock price and macroeconomic variables: autoregressive distributed lag (ARDL) bounds test. Kajian Malaysia: Journal of Malaysian Studies, 33(1), 85-103.

Çifter, A. \& Özün, A. (2008). Estimating the effects of interest rates on share prices in turkey using a multi-scale causality test. Review of Middle East Economics and Finance, 4(2), pp. 68-79.

Coskun, M., Kiraci, K., \& Muhammed, U. (2016). Seçilmis Makroekonomik Degiskenlerle Hisse Senedi Fiyatlari Arasindaki lliski:Türkiye Üzerine Ampirik Bir Inceleme. Finans Politik \& Ekonomik Yorumlar, 53(616), 61.
Das, A. (2005). Do stock prices and interest rates possess a common trend?. Recherches Économiques de Louvain/ Louvain Economic Review, 71(4), 383-390.

Daubechies, I. (1992). Ten lectures on wavelets. Philadelphia: Society for Industrial and Applied Mathematics, 61, 198-202.

Erdem, C., Arslan, C. K., \& Sema Erdem, M. (2005). Effects of macroeconomic variables on Istanbul stock exchange indexes. Applied Financial Economics, 15(14), 987-994.

Evrim-Mandaci, P., Kahyaoglu, H., \& Cagli, E. C. (2011). Stock and bond market interactions with two regime shifts: evidence from Turkey. Applied Financial Economics, 21(18), 1355-1368.

Flannery, M. J., \& James, C. M. (1984). The effect of interest rate changes on the common stock returns of financial institutions. The Journal of Finance, 39(4), 1141-1153.

Forson, J., \& Janrattanagul, J. (2014). Selected Macroeconomic Variables and Stock Market Movements: Empirical evidence from Thailand. Contemporary economics, 8(2), 154-174.

Gan, C., Lee, M., Yong, H. H. A., \& Zhang, J. (2006). Macroeconomic variables and stock market interactions: New Zealand evidence. Investment Management and Financial Innovations, 3(4), 89-101.

Gencay, R., Selçuk, F., \& Whitcher, B. J. (2002). An introduction to wavelets and other filtering methods in finance and economics. Academic Press.

Geweke, J. (1982). Measurement of linear dependence and feedback between multiple time series. Journal of the American Statistical Association, 77(378), 304-313.

Granger, C. W. (1969). Investigating causal relations by econometric models and cross-spectral methods. Econometrica: Journal of the Econometric Society, 424-438.

Graps, A. (1995). An introduction to wavelets. IEEE Computational Science and Engineering, 2(2), 50-61.

Hacker, R. S., \& Hatemi-J, A. (2006). Tests for causality between integrated variables using asymptotic and bootstrap distributions: theory and application. Applied Economics, 38(13), 1489-1500.

Hatemi-J, A. (2008). Tests for cointegration with two unknown regime shifts with an application to financial market integration. Empirical Economics, 35(3), 497-505.

Hatemi-J, A. (2012). Asymmetric causality tests with an application. Empirical Economics, 1-10.

Herve, D. B. G. H., Chanmalai, B., \& Shen, Y. (2011). The study of causal relationship between stock market indices and macroeconomic variables in Cote d'Ivoire: Evidence from error-correction models and Granger causality test. International Journal of Business and Management, 6(12), 146.

Hosoya, Y. (1991). The decomposition and measurement of the interdependency between second-order stationary processes. Probability Theory and Related Fields, 88(4), 429-444. 
Humpe, A. \& Macmillan, P. (2009) Can macroeconomic variables explain long-term stock market movements? A comparison of the US and Japan. Applied Financial Economics, 19(2), 111-119.

Jammazi, R., Ferrer, R., Jareño, F., \& Hammoudeh, S. M. (2017). Main driving factors of the interest rate-stock market Granger causality. International Review of Financial Analysis, 52(1), 260-280.

Jammazi, R., Tiwari, A. K., Ferrer, R., \& Moya, P. (2015). Time-varying dependence between stock and government bond returns: International evidence with dynamic copulas. The North American Journal of Economics and Finance, 33, 74-93.

Jawaid, S. T., \& UI Haq, A. (2012). Effects of interest rate, exchange rate and their volatilities on stock prices: Evidence from banking industry of Pakistan. Theoretical \& Applied Economics, 19(8).

Kasman, S., Vardar, G., \& Tunç, G. (2011). The impact of interest rate and exchange rate volatility on banks' stock returns and volatility: Evidence from Turkey. Economic Modelling, 28(3), 1328-1334.

Kumar, N.P. \& Puja, P. (2012). The impact of macroeconomic fundamentals on stock prices revisited: An evidence from Indian data. MPRA paper No. 38980, available at http:// mpra.ub.uni-muenchen.de/38980/

Lee, J., \& Strazicich, M. C. (2003). Minimum Lagrange multiplier unit root test with two structural breaks. The Review of Economics and Statistics, 85(4), 1082-1089.

Li, Y. H., Hwa, G. H., \& Hong, T. S. (2017). The nexus of capital flows, real interest rate and stock price performance: evidence from Malaysia. Advanced Science Letters, 23(4), 2671-2675.

Lynge, M. J., and Zumwalt, J. K. (1980). An empirical study of the interest rate sensitivity of commercial bank returns: $A$ multi-index approach. Journal of Financial and Quantitative analysis, 15(3), 731-742.

Mallat, S. G. (1989). A theory for multiresolution signal decomposition: the wavelet representation. IEEE transactions on pattern analysis and machine intelligence, 11(7), 674-693.

Mohanamani, P., \& Sivagnanasithi, T. (2012). Indian stock market and aggregates macroeconomic variables: Time series analysis. IOSR Journal of Economics \& Finance, 3(6), 68-74.

Moya-Martínez, P., Ferrer-Lapeña, R., \& Escribano-Sotos, F. (2015). Interest rate changes and stock returns in Spain: A wavelet analysis. BRQ Business Research Quarterly, 18(2), 95-110.

Muradoglu, G., Taşkın, F., \& Bigan, I. (2000). Causality between stock returns and macroeconomic variables in emerging markets. Russian \& East European Finance and Trade, 36(6), 33-53.

Özer, A., Kaya, A., \& Özer, N. (2011). Hisse senedi fiyatları ile makroekonomik değişkenlerin etkileşimi. Dokuz Eylül Üniversitesi IïBF Dergisi, 26(1), 163-182.
Özer, M., \& Kamisli, M. (2015). Frequency domain causality analysis of interactions between financial markets of Turkey. International Business Research, 9(1), 176. DOI: https://doi.org/10.5539/ibr.v9n1p176

Özün, A., \& Çifter, A. (2006). Bankaların hisse senedi getirirlerinde faiz oranı riski: Dalgacıklar analizi ile Türk bankacılık sektörü üzerine bir uygulama. Bankacılar Dergisi, 59, 3-15.

Percival, D. B., \& Mofjeld, H. O. (1997). Analysis of subtidal coastal sea level fluctuations using wavelets. Journal of the American Statistical Association, 92(439), 868-880.

Poyraz, E., \& Tepeli, A. G. Y. (2014). Seçilmiş makro ekonomik göstergelerin borsa İstanbul XU100 endeksi üzerindeki etkisinin analizi. Paradoks Ekonomi, Sosyoloji ve Politika Dergisi, 11(2), 102-128.

Rahman, M., \& Mustafa, M. (1997). Dynamic linkages and Granger causality between short-term US corporate bond and stock markets. Applied Economics Letters, 4(2), 89-91.

Ramsey, J. B. (2014). Functional representation, approximation, bases and wavelets. In Wavelet Applications in Economics and Finance (1-20). New York: Springer International Publishing.

Sensoy, A., \& Sobaci, C. (2014). Effects of volatility shocks on the dynamic linkages between exchange rate, interest rate and the stock market: The case of Turkey. Economic Modelling, 43, 448-457.

Soman, K. P., Ramachandran, K. I., \& Resmi, N.G. (2010). Insight into wavelets: from theory to practice ( $3^{\text {rd }}$ Edition). India: PHI Learning Pvt. Ltd.

Tiwari, A. K. (2012). Decomposing time-frequency relationship between interest rates and share prices in India through wavelets. MPRA paper No. 2692, available at http://www. iei1946.it/RePEc/ccg/TIWARI\%20515_531.pdf

Türkyilmaz, S. and Özata, E. (2009). Türkiye'de Para Arzi, Faiz Orani ve Hisse Senedi Fiyatlari Arasindaki Nedensel İlişkilerin Analizi. Sosyal Ekonomik Araştırmalar Dergisi, 8(16), 490-502.

Whitcher, B. J. (2005). Waveslim: Basic wavelet routines for onetwo-and three-dimensional signal processing. R Package Version, 1(3).

Wong, W. K., Khan, H., \& Du, J. (2006). Do money and interest rates matter for stock prices? An econometric study of Singapore and USA. The Singapore Economic Review, 51(01), 31-51.

Wongbangpo, P., \& Sharma, S. C. (2002). Stock market and macroeconomic fundamental dynamic interactions: ASEAN-5 countries. Journal of Asian Economics, 13(1), 27-51.

Yildiz, A. (2014). BIST100 endeksi ile alternatif yatırım araçlarının ilişkisi. Süleyman Demirel Üniversitesi İktisadi ve İdari Bilimler Fakültesi Dergisi, 19(2). 